\title{
Plano de desenvolvimento agrícola: \\ a experiência de Pitangueiras, Paraná
}

\section{Agricultural development plan: the experience of Pitangueiras country, Parana}

\author{
Marli Candalaft Alcantara Parra Peres ${ }^{1 *}$; Ricardo Ralisch²; Cristovon Videira Ripol ${ }^{3}$
}

\section{Resumo}

\begin{abstract}
A partir de 1990 o conceito de desenvolvimento passou a considerar além dos aspectos econômicos os sociais e ambientais. Diante deste enfoque os municípios do Paraná passaram a elaborar seu plano de desenvolvimento com assessoria da Empresa Paranaense de Assistência Técnica e Extensão Rural (EMATER-PR). O município de Pitangueiras, objeto deste estudo, elaborou seu plano de desenvolvimento agrícola (PDA) no ano de 1994.0 objetivo deste relato é apresentar o processo de elaboração e implantação do plano de desenvolvimento agrícola (PDA) do município de Pitangueiras, Paraná e com isto subsidiar outros trabalhos de desenvolvimento agrícola. Para o desenvolvimento deste estudo foram realizadas pesquisas documentais nos arquivos da Emater-PR e Prefeitura Municipal de Pitangueiras e entrevistas com informantes chaves. O PDR de Pitangueiras promoveu um aumento do valor bruto da produção (VBP) e estimulou a mudança de sistema de produção que era baseado no cultivo do algodão e pastagem.
\end{abstract}

Palavras-chave: Política Pública, desenvolvimento rural, política municipal

\begin{abstract}
Since 1990 the development concept has to be considered with social and environmental aspects beyond the economic one. Given this approach the counties of Paraná State started to organize their development plan with the guidance from Empresa Paranaense Technical Assistance and Rural Extension (EMATERPR). Pitangueiras county developed its plan of agricultural development (PDA) in 1994. The objective of this report is to present the process of developing and implementing this PDA, and to subsidize other works of agricultural development plans. Documentary research in the archives of Emater-PR and in the Mayor of Pitangueiras were done, as well as interviews key informants. The PDA of Pitangueiras promoted an increase in the gross value of production (GVP) and stimulated the change of production system that was establisched on cotton crop and pastures.
\end{abstract}

Key words: Public politics, rural development, municipal policy

\footnotetext{
1 Enga Agrônoma, Doutoranda em Agronomia na Universidade Estadual de Londrina UEL e Extensionista Regional do Instituto de Assistência Técnica e Extensão Rural do Paraná - EMATER Londrina - Pr. E-mail: marliparraperes@emater.pr.gov.br

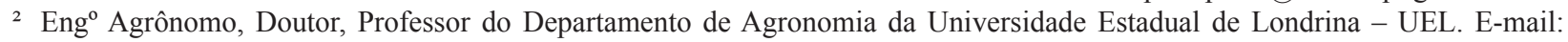
ralisch@uel.br

3 Eng ${ }^{\circ}$ Agrônomo, Extensionista Municipal do Instituto Paranaense de Assistência Técnica e Extensão Rural do Paraná - EMATER. Pitangueiras-Pr. E-mail: pitangueiras@emater.pr.gov.br

* Autor para correspondência
} 


\section{Introdução}

A partir dos anos de 1990 o conceito de desenvolvimento fundamentado no crescimento econômico foi se modificando, sendo incorporado uma série de aspectos sociais: emprego, necessidades básicas, saúde, educação e equidade social. Mais recentemente, percebeu-se que as bases ambientais de qualquer progresso futuro poderiam estar sendo comprometidas por um crescimento econômico predatório de recursos naturais e altamente poluidores surgindo então o termo desenvolvimento sustentável que tem como eixo central a melhoria da qualidade de vida humana, obedecendo aos limites da capacidade de suporte dos ecossistemas sendo que as pessoas beneficiárias também são instrumentos do processo (ASSIS, 2006). O autor considera que para ter desenvolvimento sustentável é necessário estabelecer interdependência entre o crescimento econômico, justiça social e conservação dos recursos naturais.

Desta forma os autores Santos; Schmitz; Bernartt (2003); Colombo (2006) concluem que quando se pensa em desenvolvimento sustentável deve-se pensar na interação de fatores ambientais, sociais e econômicos. Isto implica no reconhecimento da diversidade das condições econômicas, humanas, ambientais, tecnológicas e culturais, isto é, promove a garantia de renda suficiente para sua reprodução, melhorando a qualidade de vida, eliminando a contaminação do meio ambiente e produção de alimentos sadios.

Diante desta nova visão de desenvolvimento, a Empresa Paranaense de Assistência Técnica e Extensão Rural (Emater-PR), na década de 1990, desenvolveu um novo modelo de extensão em que o homem passou a ser considerado como sujeito de todo o processo na busca de seus objetivos tendo como conseqüência a melhoria de qualidade de vida (FIALHO, SANTOS; TRENTO, 1992). Destacase nesta época o intenso trabalho da extensão rural na elaboração dos planos de desenvolvimento municipais rurais ou agrícolas e organização dos conselhos municipais de desenvolvimento rural. Nestes planos estão registradas as decisões da sociedade local sobre o que se pensa fazer, como fazer, quando fazer, com quem fazer e como gerenciá-lo.

Em decorrência da Constituição Federal (1988), o Plano Municipal de Desenvolvimento Rural (no âmbito do Plano Diretor Municipal) passou a constituir instrumento básico utilizado pelo Conselho Municipal Desenvolvimento Rural (CMDR) para viabilizar a participação articulada das forças locais, com a finalidade de desenvolver o meio rural. É no CMDR que ocorre às discussões e formulação de políticas rurais, cabendo aos conselheiros a elaboração e a coordenação do Plano, com a participação efetiva dos integrantes da comunidade envolvida (FERREIRA; CARDOSO, 2004).

Dentre os vários municípios do Estado do Paraná que constituíram seus planos de desenvolvimento, selecionamos para este estudo o plano de desenvolvimento agrícola do município de Pitangueiras, devido o mesmo ter sido o resultado de discussões e debates ocorrido na sociedade de Pitangueiras. Nos anos de 1993/94, esse município, passava por uma crise econômica devido à decadência da cultura do algodão que ocupava $40 \%$ da área total de cultura anual do município e a baixa produtividade das pastagens que na época eram as atividades econômicas importantes para o município (EMATER-PR, 2005). Além do aspecto econômico o município também enfrentava problemas ambientais. Calzavara (2003) em seu estudo sobre a dinâmica regional e desenvolvimento rural sustentável da bacia do ribeirão Bandeirantes do Norte, onde o município de Pitangueiras está inserido, observou que o processo de ocupação do solo nesta bacia ocorreu de forma predatória a partir da implantação de cafezais pelo sistema de plantio em quadra sem considerar o relevo causou um processo de degradação ambiental principalmente em solo proveniente do arenito. O mesmo autor cita que este processo de degradação aliado aos 
problemas econômicos, técnicos e político conduziu a decadência da cafeicultura regional que foi substituída por lavouras anuais através de políticas públicas de incentivo a mecanização e as culturas de soja e trigo para solos de basalto e pastagens extensivas para criação de bovinos nos solos de arenito.

Pressionada pela situação de dificuldade econômica do município a unidade municipal da Emater-PR em parceria com a prefeitura municipal organizou o plano de desenvolvimento agrícola (PDA) para Pitangueiras no ano de 1994 sendo que sua vigência se estendeu até o ano de 2002.

Esse estudo tem como objetivo apresentar o processo de elaboração e implantação do plano de desenvolvimento agrícola (PDA) do município de Pitangueiras, Paraná e com isto subsidiar outros trabalhos de desenvolvimento agrícola.

\section{Relato do Caso}

O município de Pitangueiras teve seu início em 13 de dezembro de 1943 como distrito do município de Rolândia. Seu processo de emancipação concluído em 28 de setembro de 1990, através da Lei Estadual 9.389 (MONTANHA, 1996).

O município de Pitangueiras, de acordo com os dados do IBGE(1996) estálocalizado na Mesorregião Norte-Central Paranaense, possui um total de
$12.373,60$ ha sendo $10.893,00$ ha explorados com lavouras anuais e permanentes de forma intensiva, correspondendo a $88 \%$ da área total do município. Possui 206 estabelecimentos agropecuários e uma população total de 2.418 habitantes sendo 1.641 urbanos e 777 rurais (IBGE, 2000).

Segundo a Emater-PR (2005) o município possui um total de 390 agricultores, entendendose como agricultor aquele que trabalha na lavoura independente da posse da terra. Do total 91,28\% pertencem à categoria de agricultores familiares conforme caracterização da categoria descrita na lei $\mathrm{n}^{\mathrm{o}}$. 11326 de 24 de julho de 2006. O município possuía ainda 630 trabalhadores rurais volantes.

O Valor Bruto da Produção Agropecuária Municipal-VBP da safra 2003/2004, ano base 2.004, para fins de composição dos índices de participação dos municípios no produto do ICMS Fundo de Participação dos municípios (FPM) foi de $\mathrm{R}$ \$ 40,96 milhões contra $\mathrm{R} \$ 36,77$ milhões na safra 2002/2003 e R\$ 4,75 milhões na safra 1.993/1.994 (ANDRETTA, 2005). De acordo com a Emater (2005) a cultura da soja representa a principal atividade em expressão econômica local, seguidos da avicultura de corte, cultura do trigo, cultura do milho safra normal e safrinha, cultura do café e bovinocultura de corte (Tabela 1). O município ocupa a $144^{\mathrm{a}}$ posição no Estado quanto ao índice de desenvolvimento humano (IDH-M) cujo valor é 0,754 (IPARDES, 2007).

Tabela 1. Principais atividades, número de agricultores, dimensão da atividade, produtividade média e valor bruto da produção (VBP) do município de Pitangueiras - PR, ano base 2004.

\begin{tabular}{|c|c|c|c|c|}
\hline Atividade & $\begin{array}{l}\text { Número de } \\
\text { agricultores }\end{array}$ & Área total & $\begin{array}{l}\text { Produtividade } \\
\text { Média kg/ha }\end{array}$ & $\begin{array}{l}\text { VBP - RS } \\
\text { (milhões) }\end{array}$ \\
\hline Soja & 175 & 8.600 ha & 2.000 (estiagem) & 15,29 \\
\hline Aves Corte & 75 & $\begin{array}{l}2,53 \text { milhões de } \\
\text { cabeças }\end{array}$ & - & 8,54 \\
\hline Trigo & 70 & 4.260 ha & 2.060(estiagem) & 4,90 \\
\hline Café & 192 & 680 ha & 3.000 & 2,80 \\
\hline Milho Normal & 36 & 800 ha & 7.000 & 2,30 \\
\hline Milho Safrinha & 72 & 2.480 ha & 4.250 & 1,31 \\
\hline Bovino Corte & 59 & 3.410 cabeças & 3,25 cabeças/ha & 1,70 \\
\hline Total & 390 & - & - & 36,86 \\
\hline
\end{tabular}

Emater-PR (2005) 
O município é classificado como município agrícola, pois o principal ramo de atividade econômica é a agropecuária conforme demonstra a Tabela 2, onde se observa que o produto interno bruto (PIB) da agropecuária corresponde à 71,4\% do PIB total do município.

Tabela 2. Produto interno bruto do município de Pitangueiras-Pr a preços básicos segundo os ramos de atividades ano base 2004.

\begin{tabular}{cc}
\hline Ramos de atividades & Valor (R\$ 1,00) \\
\hline Agropecuária & 28.676 .646 \\
Indústria & 2.456 .005 \\
Serviços & 9.016 .649 \\
\hline Total & 40.149 .344 \\
\hline
\end{tabular}

Ipardes (2007)

Para o desenvolvimento deste trabalho foram realizadas pesquisas documentais nos arquivos da Emater-PR de Pitangueiras e prefeitura municipal, obtendo se assim dados de registros dos levantamentos e dos trabalhos realizados junto com as comunidades, principalmente entre os anos de 1994 a 2002, o que permitiu inclusive uma análise da dinâmica da população. Foram analisados relatórios anuais de trabalho, convites dos eventos realizados, livro de registros dos certificados dos cursos realizados pela Emater-PR, documento de realidade municipal, banco de reportagens jornalísticas sobre o município, documento original do PDA de Pitangueiras, relatório de Prestação de Contas da Prefeitura Municipal referente ao ano de 1996 e o decreto numero 324/96 de 06/08/1996 que criou o Conselho Municipal do Projeto Paraná 12 Meses. Entrevistas também foram realizadas com informantes chaves com o extensionista municipal da Emater-PR que coordenou todo o processo de elaboração e condução do PDA de Pitangueiras, o Prefeito atual que na época da elaboração do plano também era prefeito e o presidente da Associação de Cafeicultores de Pitangueiras (ACAPI) que é um agricultor.

A construção do plano de desenvolvimento agrícola para o município de Pitangueiras (PDA) foi realizada de forma democrática buscando a descentralização do planejamento através de metodologias participativas. Além dos agricultores fizeram parte da elaboração e implantação do plano as seguintes entidades: Secretaria de Estado de Agricultura e Abastecimento (SEAB), Instituto Paranaense de Assistência Técnica e Extensão Rural (Emater), Instituto Agronômico do Paraná (IAPAR), Conpanhia de Desenvolvimento Agropecuário do Paraná (CODAPAR), Secretaria Estadual do Emprego e Relações do Trabalho, Secretaria Estadual do Meio Ambiente (SEMA), Instituto Ambiental do Paraná (IAP), Prefeitura Municipal de Pitangueiras, Câmara de Vereadores de Pitangueiras, Banco do Brasil, Banco do Estado do Paraná, Cooperativa Corol, Associação de Desenvolvimento Comunitário de Pitangueiras, Abatedouro Big Frango, Abatedouro Comaves, Abatedouro Avebom, Kanebo Silk do Brasil, Fiação de Seda Bratac, Agroceres, Sindicato dos Trabalhadores Rurais e Patronal de Astorga.

A primeira etapa de construção do plano se constituiu na elaboração do diagnóstico do setor rural do município que se consolidou com o do levantamento dos dados primários e secundários. Os dados secundários como a área geográfica, as atividades agropecuárias existentes, formação histórica do município, tipo de solo, clima, relevo, recursos hídricos, caracterização sócio econômica da população rural, infra-estrutura e organizações de produtores existentes foram obtidos por meio de 
pesquisas bibliográficas e pesquisas nos arquivos da Prefeitura Municipal de Pitangueiras e nos arquivos da unidade municipal da Emater-PR de Pitangueiras no ano de 1994.

A segunda etapa se caracterizou em detectar as prioridades do plano e a visão dos agricultores sobre a situação agropecuária municipal. Na época estas informações foram obtidas com a realização de sete reuniões em comunidades rurais do município, nas quais, utilizando a metodologia do diagnóstico rural participativo foi possível hierarquizar os problemas de ordem econômica, social e ambiental que a população rural enfrentava. As reuniões foram realizadas durante o segundo semestre do ano de 1994. Elas ocorreram logo após a geada que ocorreu em julho deste mesmo ano que atingiu os cafezais do município, gerando prejuízos econômicos aos agricultores e servindo de estímulo a participarem das reuniões de diagnóstico devido às dificuldades, principalmente de ordem econômica. As reuniões foram realizadas nas comunidades Mamão, Laranjeiras, Magnólia, Canaby, Morango, periferia do município e sede do município.

Todas as reuniões foram coordenadas pela Emater-PR e Prefeitura Municipal, pois na época não existia Conselho Municipal de Desenvolvimento Rural formal, o mesmo só passou a existir a partir do ano de 1996 através de um decreto municipal $\mathrm{n}^{\circ}$. 324/96 que criou o Conselho Municipal do Programa Paraná 12 Meses, que também passou a executar o papel do conselho de desenvolvimento rural. Como resultados das reuniões foram identificados os principais problemas dos agricultores: a) baixo nível de produtividade das lavouras; b) baixa renda dos trabalhadores rurais; c) baixa renda familiar e descapitalização dos pequenos agricultores; d) agricultores que possuíam a posse da terra passaram à condição de assalariados, aumentando o êxodo rural, e) intoxicação humana e de animais por agroquímicos e poluição de mananciais de água, degradação do solo; f) associativismo em declínio; g) dificuldades no setor leiteiro; h) desemprego; i) sazonalidade na demanda de mão de obra volante.
Com estas informações foi possível redigir o PDA de Pitangueiras no ano de 1994, tendo como signatários o prefeito municipal, o viceprefeito, o presidente da Comissão Municipal de Solos, o presidente da câmara de vereadores e os dois extensionistas da Emater-PR de Pitangueiras. $O$ período de execução determinado era entre 1995 e 1998 (PREFEITURA MUNICIPAL DE PITANGUEIRAS, 1994). O plano tinha como objetivos gerais: a) promover a melhoria de renda de pequenas propriedades rurais através de diversificação; b) aumentar a produtividade das lavouras de algodão e café e de criações como gado de corte e de leite; c) reduzir os custos das atividades agropecuárias; d) desenvolver ações que contribuíssem na qualidade e competitividade da produção agropecuária local; e) estimular o desenvolvimento da consciência associativista entre os agricultores para o acesso aos meios de produção; f) dar condições de acesso ao crédito rural de pequenos produtores; g) promover a qualificação técnica dos agricultores; h) estimular a recuperação do solo agrícola e a redução do assoreamento de mananciais de água; i) reduzir a poluição dos riachos e a intoxicação de pessoas e animais causados por agrotóxicos. Apesar de o plano ter sido nominado plano de desenvolvimento agrícola em seus objetivos, ficou caracterizado mais como um plano de desenvolvimento rural, pois segundo Navarro (2001) desenvolvimento agrícola refere-se exclusivamente às condições da produção agrícola no sentido exclusivamente produtivo e o desenvolvimento rural sustentável utiliza a equidade social, não esquecendo do componente ambiental, o qual ficou enfatizado nos objetivos do plano.

O plano foi concebido com a criação de quatro programas municipais voltados ao aumento da circulação de riquezas no município com sustentabilidade econômica e ambiental e melhoria da qualidade de vida dos agricultores. Estes programas foram criados para resolver os problemas citados nos diagnósticos rurais participativos realizados anteriormente ao plano. 
Os programas que compõe o PDA de Pitangueiras são: diversificação do estabelecimento agrícola, organização rural, recuperação e conservação dos recursos naturais e programa de recuperação da cotonicultura municipal.

Estes programas municipais passaram a ser implantados a partir do ano 1995 após a realização do primeiro encontro de agricultores para debater a diversificação agrícola do município de Pitangueiras. O encontro foi realizado no dia 29 de setembro de 1995 e tinha como objetivos discutir o diagnóstico da realidade municipal, seus problemas e potencialidades; apresentar e debater alternativas para diversificação de explorações e renda da atividade agropecuária potenciais para o município; promover a organização dos produtores e da produção para a transformação e comercialização dos produtos. $\mathrm{O}$ encontro teve a participação de 150 agricultores e foram discutidas as culturas do algodão, café adensado, laranja e mandioca para a indústria, leite, suinocultura, fruticultura, bicho da seda e hortaliças. No final do encontro os participantes se inscreveram nos grupos de interesse por atividade agropecuária, constituindo assim os grupos de agricultores com interesse comum (EMATER-PR, 1995).

Vencida a etapa de organização dos grupos de produtores, os mesmos passaram a ser atendidos individualmente com a participação dos diversos segmentos das cadeias produtivas afins, como agroindústria, cooperativas e abatedouros. Os encontros destes grupos foram organizados pelo extensionista daEmater. Reuniões periódicas por fase produtiva das atividades que estavam em formação eram agendadas de acordo com a necessidade do grupo. Após as reuniões os agricultores recebiam visitas individuais do extensionista da Emater-PR ou da cooperativa, se cooperado, para acompanhar o desenvolvimento da cultura. As visitas realizadas pela Emater-PR durante os anos de vigência do plano que constavam nos relatórios de atividades anuais da organização somavam 250 por ano. As visitas realizadas pelas cooperativas agropecuárias como a cooperativa Corol, Integrada e Nova Produtiva não se tem registro. Além das visitas as unidades produtivas os agricultores também freqüentavam as unidades municipal da Emater-PR e cooperativa Corol existentes no município. Para aperfeiçoar os conhecimentos técnicos dos agricultores e propiciar um aumento de sua capacidade produtiva, estes grupos eram convidados a participarem de cursos de iniciação ou aperfeiçoamento de atividades agropecuárias. Estes cursos eram organizados pela Emater-PR e contavam também com o apoio da Prefeitura Municipal de Pitangueiras e Secretaria Estadual de Relações de Emprego. Treinamentos por meio de cursos foi a metodologia mais rápida $\mathrm{e}$ eficiente que se encontrou para treinar os agricultores que estavam iniciando ou aperfeiçoando atividades produtivas elencadas no primeiro encontro de agricultores para debater diversificação. Os instrutores dos cursos eram preferencialmente os extensionistas da Emater-PR e em alguns casos pesquisadores principalmente do Instituto Agronômico do Paraná e Empresa Brasileira de Pesquisa Agropecuária Foram realizados 35 cursos durante os anos de 1996 a 2005. Dentre os cursos realizados destacam-se os cursos de formação de conselheiros que tinha como objetivo treinar as lideranças agropecuárias locais para formar o Conselho de Desenvolvimento Rural. Apesar de o treinamento ter sido realizado com um bom número de participantes não foi possível formar o Conselho de Desenvolvimento Rural de Pitangueiras devido a falta de interesse dos participantes e por já existir o Conselho do Programa Estadual Paraná 12 Meses, organização consultiva das questões relacionadas ao desenvolvimento rural de Pitangueiras.

Em complementação aos cursos foram realizados encontros municipais de agricultores, dias de campo e excursões técnicas com objetivo de complementar as orientações técnicas e discutir os assuntos da agropecuária municipal de forma a abranger todos os agricultores do município. Com exceção das excursões que eram realizadas para grupos de agricultores mais selecionados, para os 
outros eventos todos os agricultores do município eram convidados a participar.

Do total dos quinze eventos realizados quarenta por cento foi relacionado a assuntos ligados à cultura do café no sistema adensado, pois as características e histórico do município apresentavam um grande potencial para o cultivo do café, além disto, na época existia um Programa Estadual de Revitalização da Cultura do Café o qual foi trabalhado no município pelas cooperativas e Emater-PR.

Para a implementação dos quatro programas municipais de desenvolvimento foram utilizados recursos de diversas fontes sendo aplicados aproximadamente R \$ 5.000.000,00 (cinco milhões), sendo novecentos mil do Programa Nacional da Agricultura Familiar (PRONAF); R\$ 722.000,00 do Programa Paraná 12 Meses e o restante foi a contrapartida dos agricultores, governo municipal e estadual.

OsprogramasParaná12MeseseoPRONAF foram fundamentais para viabilizar o desenvolvimento dos cafeicultores e a diversificação do município que elaborou o PDA como um instrumento de real planejamento para o desenvolvimento rural de Pitangueiras e não para habilitar o município a receber recursos do PRONAF Infraestrutura. É importante destacar que todo o trabalho de extensão rural realizado no município baseou-se no PDA, os programas de governo estadual e federal foram utilizados de forma a atender os projetos mencionados no plano.

A conclusão do PDA se deu no ano de 2002. Não foi realizado nenhum processo de avaliação formal do mesmo, sendo uma fase importantíssima para subsidiar um novo plano que o município planeja elaborar. Segundo Martin et al. (1998) a etapa de avaliação de um plano é fundamental para o sucesso do mesmo, pois nenhum plano é acabado e eterno, deve estar em constantes reavaliações dos rumos e metas propostas.

\section{Discussão e Conclusão}

A principal análise que o município de Pitangueiras fez e divulga como resultados do PDA é a evolução econômica do município, considerando o indicador valor bruto da produção (VBP), que na safra 1993/94 apresentava o valor de quatro milhões e setenta e cinco mil reais passando para trinta e seis milhões e setenta e sete mil reais na safra 2002/03 (ANDRETTA, 2005). Este indicador é importante, mas é necessário considerar outros aspectos que o plano propunha como a melhoria de qualidade de vida e recuperação ambiental que não são considerados no VBP. É necessário fazer estudos que mostrem a evolução destes aspectos sociais e ambientais em Pitangueiras.

A construção e execução do PDA de Pitangueiras trouxeram alguns resultados importantes, como a mobilização de toda a sociedade rural de Pitangueiras para discussão e execução do plano, a sensibilização das autoridades na recuperação da economia agrícola municipal, a criação da associação dos cafeicultores de Pitangueiras, a criação de duas vilas rurais e criação do terminal do trabalhador volante.

A metodologia de diagnóstico rural participativo utilizada para o diagnóstico do município deu oportunidade para todas as comunidades rurais contribuírem com informações para a formulação do plano e garantiu a participação dos agricultores nas ações de implementação do plano, sendo os mesmos cúmplices dos resultados.

Os cursos e eventos realizados para a capacitação dos agricultores proporcionaram uma nova visão de agricultura e estimularam os agricultores a procurarem novas alternativas de cultivo em substituição ao algodão e pastagens degradadas, propiciando um aumento de VBP (valor bruto da produção) do município com um incremento de $885,32 \%$ em um período de 12 anos, isto é do ano de 1994 ao ano de 2002. 
O nome dado ao plano como Plano de Desenvolvimento Agrícola foi utilizado de forma errada, pois o plano não se referiu só a aspectos agrícolas, mas também abrangeu aspectos ambientais e sócios econômicos sendo que o nome correto para o mesmo deveria ser Plano de Desenvolvimento Rural de Pitangueiras. É necessário que se realize uma avaliação do plano para que sirva de subsídio na elaboração de outro subseqüente.

\section{Referências}

ANDRETTA, G. C. Valor bruto da produção agropecuária paranaense de 2004. Curitiba: SEAB/ DERAL/DEB. 2005.

ASSIS, R. L. Desenvolvimento rural sustentável no Brasil: perspectivas a partir da integração de ações públicas e privadas com base na agroecologia. Economia Aplicada, Ribeirão Preto, v. 10, n. 1, p. 75-89, jan./mar. 2006.

BRASIL. Constituição (1988). Constituição da República Federativa do Brasil. 27 ed. São Paulo: Saraiva, 1991.

BRASIL. Decreto-lei no. 11.326, de 24 de julho de 2006. Estabelece as diretrizes para a formulação da Política Nacional da Agricultura Familiar e Empreendimentos Familiares Rurais. Diário Oficial da República Federativa do Brasil, Brasília, 24 jul. 2006.

CALZAVARA, O. Processos emergenciais de sustentabilidade na dinâmica agrária do norte do Paraná. 2003. Tese (Doutorado em Agronomia) - Universidade Estadual de Londrina, Londrina.

COLOMBO, S. Crescimento, desenvolvimento e meio ambiente. Revista Eletrônica Mestrado em Educação Ambiental, Rio Grande do Sul, v. 17, p. 274-285, jul./ dez. 2006.

FERREIRA, J. A.; CARDOSO, J. L. Papel do conselho municipal de desenvolvimento rural: a experiência de Espírito Santo do Pinhal, Estado de São Paulo. Informações Econômicas. São Paulo, v. 34, n. 1, p. 1827, jan. 2004.
FIALHO, J. T., SANTOS, L. M. F.; TRENTO, E. J. Extensão rural no Paraná: um modelo ambiental. Curitiba: Emater, 1992. 36p.

INSTITUTO BRASILEIRO DE GEOGRAFIA E ESTATÍSTICA - IBGE. Censo agropecuário 1996. Brasília: IBGE, 1996.

2000.

Censo demográfico 2000. Brasília: IBGE,

INSTITUTO PARANAENSE DE ASSISTÊNCIA TÉCNICA E EXTENSÃO RURAL - EMATERPARANÁ. Relatório de atividades do município de Pitangueiras, ano 2005. Pitangueiras: Emater, 2005.

. Relatório de atividades, ano 1995 Pitangueiras. Pitangueiras: Emater. 1995.(EMATER Documento interno).

INSTITUTO PARANAENSE DE DESENVOLVIMENTO ECONÔMICO E SOCIAL - IPARDES. Caderno estatístico do município de Pitangueiras. Curitiba: Ipardes, 2007.

MARTIN, N. B.; OTANI, M. N.; SERRA, R.; ANGELO, J. A. Subsídios para elaboração de plano diretor agrícola municipal. Informações Econômicas. São Paulo, v. 28, n. 4, p. 40-53, abr. 1998.

MONTANHA, L. A. Relatório de prestação de contas de Pitangueiras. Arapongas: Gazeta da Cidade. 1996. 18 p.

NAVARRO, Z. Desenvolvimento rural no Brasil: os limites do passado e os caminhos do futuro. Estudos Avançados, São Paulo: USP, v. 15, n. 43, p.83-100, set./ dez. 2001.

PREFEITURA MUNICIPAL DE PITANGUEIRAS. Plano de desenvolvimento agricola para o município de Pitangueiras, PR. Pitangueiras: Prefeitura Municipal de Pitangueiras, $1994.20 \mathrm{p}$.

SANTOS, M. F.; SCHMITZ, E.; BERNARTT, M. L. Desenvolvimento rural sustentável e suas diferentes concepções. In: SEMINÁRIO DO I CURSO DE ESPECIALIZAÇÃO EM DESENVOLVIMENTO RURAL, 1., 2003, Pato Branco. Anais... Pato Branco: CEFET-PR/CEPAD/IMPREDEL, 2003. p. 201-211. 